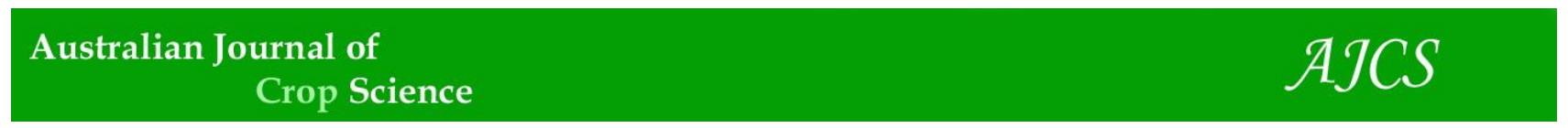

AJCS 14(07):1140-1149 (2020)

ISSN:1835-2707

doi: 10.21475/ajcs.20.14.07.p2366

\title{
Application of metal nanoparticles for pre-sowing treatment of spring barley seeds
}

\author{
Arthur Gagikovich Yablokov, Olga Aleksandrovna Bogoslovskaya ", Irina Pavlovna Olkhovskaya, Natalya \\ Nikolaevna Glushchenko
}

\author{
V.L. Talrose Institute for Energy Problems of Chemical Physics at N.N. Semenov Federal Research Center \\ for Chemical Physics, Russian Academy of Sciences, 119334, 38/2 Leninsky pr., Moscow, Russian \\ Federation
}

\section{*Corresponding author: obogo@mail.ru}

Abstract

This paper presents data on the pre-sowing treatment of spring barley (Hordeum vulgare L.) seeds by polymer coating with metal nanoparticles (NPs) affecting on seed germination and morphometric parameters of seedlings. Metal NPs [Fe ( $56.0 \pm 0.9 \mathrm{~nm}$, phase composition: $\left.\mathrm{Fe}^{0}-27.9 \pm 2.1 \%, \mathrm{Fe}_{3} \mathrm{O}_{4}-72.1 \pm 3.6 \%\right) ; \mathrm{Zn}\left(60.6 \pm 3.7 \mathrm{~nm}\right.$, phase composition: $\left.\mathrm{Zn}^{0}-100 \%\right) ; \mathrm{Cu}(65.0 \pm 1.2 \mathrm{~nm}$, phase composition: $\left.\mathrm{Cu}^{0}-100 \%\right)$ ] were incorporated into a polymer coating about 10 microns thick, consisting of Na-carboxymethyl cellulose (Na-CMC) and polyethylene glycol-400 (PEG-400), with a dye rhodamine 6G (Rh6G). We developed and studied polymer compositions as with individual NPs in concentrations $10^{-4} \%-10^{-10} \%$ and their combinations. To compare effects of NPs with metal ions, we tested polymer film coating with metal sulfates in equivalent amounts. Pre-sowing treatment of barley seeds with metal NPs or metal ions in the polymer coating affected germination, fresh green and root mass (FM and RM) of seedlings. Film thickness was less than $10 \%$ of the caryopsis shell. The surface of seeds treated with the polymer composition was uniform. The defects and irregularities were smoothed. There were no significant differences in the endosperm structure on sections of the treated and control samples. Iron, zinc and copper NPs composition at $10^{-8} \%, 10^{-4} \%$ and $10^{-8} \%$ concentrations were the best in laboratory experiments. In the field trials, it stimulated barley crop yields and decreased the moisture content of the bunker grain compared with the control.

Keywords: Spring barley, iron nanoparticles, copper nanoparticles, zinc nanoparticles, seed germination, sprout and root mass.

Abbreviations: ANOVA_analysis of variance; CuO_copper oxide; DS_degree of substitution; EDTA-Na 2 _disodium salt of ethylenediaminetetraacetic acid; FM_sprout fresh mass; $\mathrm{mPa} \cdot \mathrm{s}$ _millipascal second; MW_molecular weight; NaCMC_carboxymethyl cellulose sodium salt; NPs_nanoparticles; PEG-400_polyethylene glycol; Rh6G_rhodamine 6G; RM_root mass; SG_seed germination; TEM_Transmission electron microscopy; ZnO_zinc oxide.

\section{Introduction}

To increase the yield and quality of agricultural production, nanotechnologies and nanomaterials become widespread (Ghormade et al., 2011; Khot et al., 2012; Handford et al., 2014; Duhan et al., 2017; Ma et al., 2018). The range of tested nanomaterials is rather versatile and includes metal oxides, magnetic particles, nanotubes, semiconductor quantum dots, etc. (Bindraban et al., 2015; Bhagat et al., 2015; Dasgupta et al., 2015). In modern agriculture $\mathrm{Zn}, \mathrm{Cu}$, $\mathrm{Fe}, \mathrm{Mn}$ or their oxides NPs are employed. NPs of zinc oxide ( $\mathrm{ZnO})$ and copper oxide ( $\mathrm{CuO}$ ) are used in commercial products, including antimicrobial agents and fungicides. They inhibit the growth of fungal plant pathogens, such as Botrytis cinerea, Penicillium expansum, Fusarium graminearum and Phytophthora infestans. NPs enhance plant growth and control infections (El-Temsah and Joner, 2012; Feng et al., 2013; Alghuthaymi et al., 2015; Elsharkaway and Derbalah, 2018). Growth stimulation and crops yield enhancement were registered for a wide range of elements, including vital, rare-earth elements and others (Azamal and Khwaja, 2014; Pradhan et al., 2017; RuttkayNedecky et al., 2017; Razzaq et al., 2016; Mehmood, 2018).
NPs effects can be explained through their unique properties. Our long-term studies of NPs have revealed the main features of metal NPs biological effects. They are characterized by toxicity lower (7-50 times) than from metal ions, prolonged and multilateral effects; stimulation of metabolic processes.

Crop yields and crop quality enhancement after NPs treatment can solve environmental problems due to reduced effective doses of metals (Dasgupta et al., 2015; Duhan et al., 2017). Nutrient medium supplemented with NPs have enhanced growth in comparison with traditional recepies. Plants processed with NPs are healthier and have improved morphometric parameters (Zhao et al., 2019). NPs biological activity is associated with their structural peculiarities and physico-chemical characteristics; metal NPs exhibit a synergistic effect with natural polysaccharides (Glushchenko et al., 2002; Rakhmetova et al., 2010; Bogoslovskaja et al., 2014; Rakhmetova et al., 2015). However, the optimal application of nanoparticles still remains unsolved. 
The aim of this study is to create new preparations for presowing treatment based on the iron, zinc and copper NPs as components of polymer coating to improve seed protection and to stimulate germination. We also studied their physical and chemical characteristics and morphometric parameters and crop yield of spring barley.

\section{Results}

\section{Physical and chemical characteristics of metal NPs}

The efficient control of physicochemical parameters of NPs is obligatory for successful applicability. Activity of metal NPs depends on physicochemical characteristics: such as size, shape, phase ratio. Fig. 1 presents electronic photographs of iron, zinc and copper NPs, size distribution curves and diffractograms.

$\mathrm{Fe}, \mathrm{Zn}, \mathrm{Cu}$ NPs in our experiments were single-crystal structures covered with an oxide film. The average particle diameter of iron was $56.0 \pm 0.9 \mathrm{~nm}$; zinc $-60.6 \pm 3.7 \mathrm{~nm}$; copper - $65.0 \pm 1.2 \mathrm{~nm}$ (Table 1).

Metal NPs have a complex structure with a metal core inside and an oxide film on the surface. According to $X$-ray phase analysis, iron NPs contains a metallic crystalline phase ( $\alpha-\mathrm{Fe}$ $-27.9 \%$ ) and the rest is iron oxide $-\gamma-\mathrm{Fe}_{2} \mathrm{O}_{3}$. Zinc NPs contain a metallic crystalline phase of zinc. Oxide in zinc NPs was not detected; it can be X-ray amorphous. Copper NPs also contain a metallic crystalline phase.

\section{Preparation of the polymer film coating with metal NPs and seed surface treatment}

For the pre-sowing treatment of seeds with metal NPs, a composition was designed based on Na-CMC and PEG-400. NPs suspensions were also introduced in various concentrations. Rh $6 \mathrm{G}$ was added to evaluate the uniformity of polymer coating on seeds. Seeds were treated with the resulting solution, ensuring uniform seed coverage and air dried to form a film.

The spectra of polymer films about 10 microns thick with metal NPs and dye, placed on the quartz plate, were studied. The absorption maximum for $\mathrm{Rh} 6 \mathrm{G}$ is at $526-528 \mathrm{~nm}$, and the emission band lies in the region of $548-550 \mathrm{~nm}$. The Stokes shift for intact dye was equal to $22 \mathrm{~nm}$. Due to the dye immobilization in the polymer film, a bathochromic shift of the absorption maximum was observed and it is equal 12 $\mathrm{nm}$, compared to its absorption spectrum in a pure solvent. A similar shift of the emission band is $37 \mathrm{~nm}$ (Fig. 2).

The observed shifts of the maxima are due to the ionic binding of the cationic dye with anionic carboxyl groups in the $\mathrm{Na}-\mathrm{CMC}$ polymer chain. At the same time a maximum $510 \mathrm{~nm}$ in the absorption spectrum indicates that some dye molecules remain in the associated state, particularly, in the form of $\mathrm{H}$-type dimers or larger molecular associates. This is confirmed by the fact that the fluorescence intensity of the dye decreases with time in the process of film formation and by displacement of the bathochromic shift of the maximum in emission band.

The formation of dye aggregates is also demonstrated by measurements of sizes of particles in polymer solutions. For the initial solution of a polymer mixture (Na-CMC/PEG-400) the main contribution to light scattering intensity is produced by particles of polymer with a size less than $10 \mathrm{~nm}$
(Fig. 3A). After zinc NPs $\left(10^{-4} \%\right)$ was added to the polymer solution, particles with a hydrodynamic diameter of about $60 \mathrm{~nm}$ become dominant (Fig. 3B). In the presence of dye (Rh6G) at a higher concentration $(50 \mu \mathrm{M})$, the light scattering signals from NPs are completely masked by signals from larger aggregates of submicron-sized dye (Fig. 3C).

Thus, the strong ionic binding of Rh6G molecules with the polymer matrix confirms uniform staining of the film on the seed surface.

\section{Coating film morphology}

The optical microscopy in reflection mode at 50x magnification showed that the seed surface is covered with a continuous film, while thickness was less than 10 micron (Fig. 4A). In the cross section, the film thickness was less than $10 \%$ of the shell (Fig. $4 \mathrm{~B}$ ). The endosperm structure of the treated seeds seems undisturbed (Fig. 4C).

According to the scanning electron microscopy data, the surface of seeds, treated with the polymer composition is more uniform, whereas the defects and irregularities was smoothed. There were no significant differences in the endosperm ultra structure on sections of the treated and control samples (Fig. 5).

The polymer coating of seeds should not only be uniformly distributed over the surface, but also should not injure germination process. Optical microscopy images demonstrated that the polymer coating is smooth (Fig. 6A), closes the micro traumas on the seed, isolates seeds from infections (Fig. 6B), and does not disturb germination (Fig. $6 C)$.

\section{Effects of metal NPs on germination and morphometry of barley in laboratory tests}

We have studied how the pre-sowing treatment with a polymer coating with $\mathrm{Fe}, \mathrm{Zn}, \mathrm{Cu}$ NPs affect on barley seed germination (SG) and fresh sprout and root mass (FM, RM) of seedlings (Table 2). Metal NPs were introduced into a polymer designed for seed coating. Polymer film itself did not affect the test parameters. Fe NPs admixture enhanced $\mathrm{FM}$ and $\mathrm{RM}$ at the $7^{\text {th }}$ day of germination. The maximum effect was observed for Fe at concentration $10^{-6} \%(0.4 \mathrm{mg} / 1$ ton of grain). Coating with Zn NPs was the best with $10^{-4} \%$ ( $40 \mathrm{mg} / 1$ ton of grain) Zn NPs. Cu NPs at $10^{-8} \%(0.004 \mathrm{mg} / 1$ ton of grain) increased $\mathrm{FM}$ by $13 \%$.

After tests, the following metal NPs concentrations were chosen: $\mathrm{Fe}-10^{-6} \%$ and $10^{-8} \% ; \mathrm{Zn}-10^{-3} \%$ and $10^{-4} \%$; $\mathrm{Cu}-10$ ${ }^{8} \%$. Coatings with these NPs contents were used for seed treatment (Table 3). Germination percentage depends on the concentration and ratio of metal NPs. At the7th day, FM and RM in the three test groups were larger by $2-21 \%$ and $11-19 \%$, than control parameters. The largest increase in FM and RM, by $21.1 \%$ and $19.1 \%$, respectively, was observed with NPs iron, zinc and copper at $10^{-8} \%, 10^{-4} \%$ and $10^{-8} \%$ concentrations.

Seeds coated with polymer film containing $\mathrm{Fe}^{2+}, \mathrm{Cu}^{2+}$ and $\mathrm{Zn}^{2+}$ in the equivalent concentrations (4th group in Table 3 ), were used to compare effects of NPs against metal ions from sulfates. The metal ions in components of seed coating stimulated FM and RM but less than metal NPs. Metal NPs showed the best stimulation of the root growth in the 3rd 
Table 1. Characteristics of metal NPs.

\begin{tabular}{lcccc}
\hline NPs & Size, $\mathrm{nm}$ & Content of crystalline metal, $\%$ & $\begin{array}{c}\text { The form of } \\
\text { oxide }\end{array}$ & Oxide form, \% \\
\hline $\mathrm{Fe}$ & $56.0 \pm 0.9$ & $27.9 \pm 2.1$ & $\mathrm{Fe}_{3} \mathrm{O}_{4}$ & $72.1 \pm 3.6$ \\
$\mathrm{Zn}$ & $60.6 \pm 3.7$ & 100 & no & - \\
$\mathrm{Cu}$ & $65.0 \pm 1.2$ & 100 & no & - \\
\hline
\end{tabular}

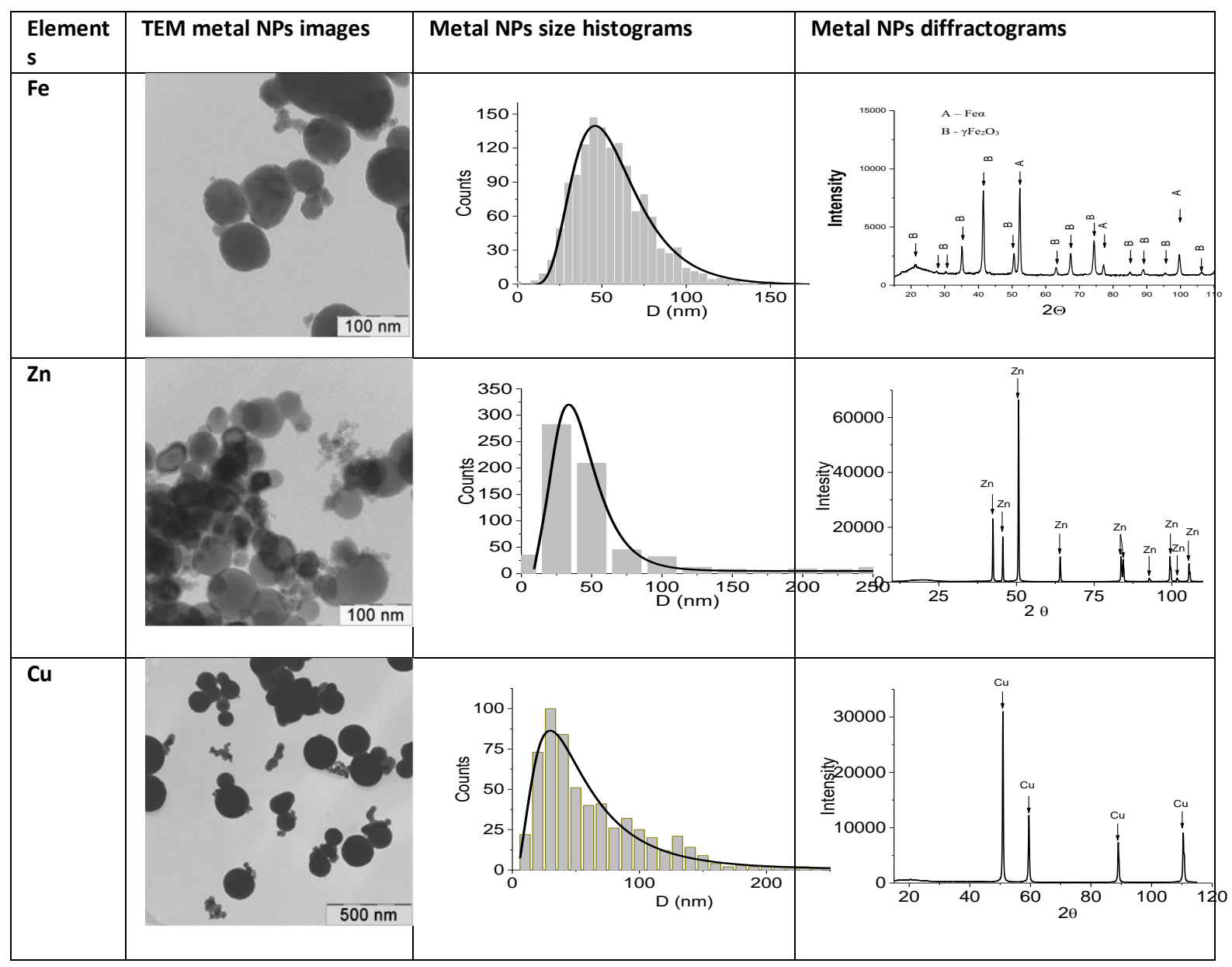

Fig 1. TEM images, size distribution histograms and diffractograms for iron, zinc and copper NPs.

Table 2. Growing parameters of barley after pre-sowing treatment by polymer coating including metal NPs*

\begin{tabular}{|c|c|c|c|c|c|}
\hline Metal NPs & $\begin{array}{l}\text { NPs content in the } \\
\text { coating, } \%(w / w)\end{array}$ & $\begin{array}{c}\text { Seed } \\
\text { germination* (3 } \\
\text { days), \% }\end{array}$ & $\begin{array}{c}\text { Seed } \\
\text { germination* (7 } \\
\text { days.), \% }\end{array}$ & $\begin{array}{c}\mathrm{FM}^{* *}, \exp / \text { cont, } \\
\%\end{array}$ & $\mathrm{RM}^{* *}, \exp /$ cont, $\%$ \\
\hline Control 1 & Nontreated seeds & $87.2 \pm 4.1 \mathrm{a}$ & $96.1 \pm 4.9$ a & $100 \pm 4.0 \mathrm{a}$ & $100 \pm 3.6 \mathrm{a}$ \\
\hline Control 2 & $\begin{array}{c}\text { Polymers film without } \\
\text { metal NPs }\end{array}$ & $86.3 \pm 7.8$ a & $95.4 \pm 4.8$ a & $101 \pm 3.4 \mathrm{a}$ & $99 \pm 4.2 \mathrm{a}$ \\
\hline $\mathrm{Fe}$ & $10^{-4}$ & $90.5 \pm 1.9$ a & $100 \pm 1.4 \mathrm{a}$ & $108 \pm 2.3 \mathrm{ab}$ & $101.5 \pm 1.3 \mathrm{a}$ \\
\hline & $\begin{array}{c}10^{-6} \\
10^{-8} \\
10^{-10}\end{array}$ & $\begin{array}{c}95.4 \pm 3.9 \mathrm{a} \\
92.8 \pm 4.7 \mathrm{a} \\
93.7 \pm 2.9\end{array}$ & $\begin{array}{c}100 \pm 1.1 \mathrm{a} \\
98.8 \pm 1.9 \mathrm{a} \\
100 \pm 4.3 \mathrm{a}\end{array}$ & $\begin{array}{l}112 \pm 2.6 \mathrm{~b} \\
100 \pm 1.1 \mathrm{a} \\
103 \pm 2.4 \mathrm{a}\end{array}$ & $\begin{array}{c}108.5 \pm 1.4 \mathrm{~b} \\
105.8 \pm 2.4 \mathrm{ab} \\
107 \pm 2.3 \mathrm{ab}\end{array}$ \\
\hline $\mathrm{Zn}$ & $\begin{array}{l}10^{-4} \\
10^{-5} \\
10^{-6}\end{array}$ & $\begin{array}{c}94.3 \pm 3.8 \mathrm{ab} \\
93.9 \pm 3.8\end{array}$ & $\begin{array}{c}100 \pm 0.9 \mathrm{ab} \\
100 \pm 3.0\end{array}$ & $\begin{array}{c}114.9 \pm 3.0 \mathrm{~b} \\
96.8 \pm 2.2 \mathrm{a}\end{array}$ & $\begin{array}{c}106.9 \pm 1.0 \mathrm{~b} \\
106.7 \pm 2.1 \mathrm{ab}\end{array}$ \\
\hline $\mathrm{Cu}$ & $\begin{array}{l}10^{-6} \\
10^{-7} \\
10^{-8}\end{array}$ & $\begin{array}{l}88.3 \pm 3.2 \\
97.4 \pm 4.3 \\
80.1 \pm 1.8\end{array}$ & $\begin{array}{l}91.8 \pm 4.2 \\
97.7 \pm 4.6 \\
88.2 \pm 3.3\end{array}$ & $\begin{array}{l}95.3 \pm 2.1 \mathrm{a} \\
102.1 \pm 2.4 \mathrm{a} \\
113.0 \pm 3.1 \mathrm{~b}\end{array}$ & $\begin{array}{c}95.4 \pm 4.5 \mathrm{a} \\
95.4 \pm 2.0 \mathrm{a} \\
100.3 \pm 1.9 \mathrm{a}\end{array}$ \\
\hline
\end{tabular}

* Experimental data were counted as a percentage of germinated seeds against number of sawed (\%).

** Experimental data were counted as a ratio of treated values against control (\%). Sprout fresh mass and root mass were calculated as [total mass/number of germinated seeds] 


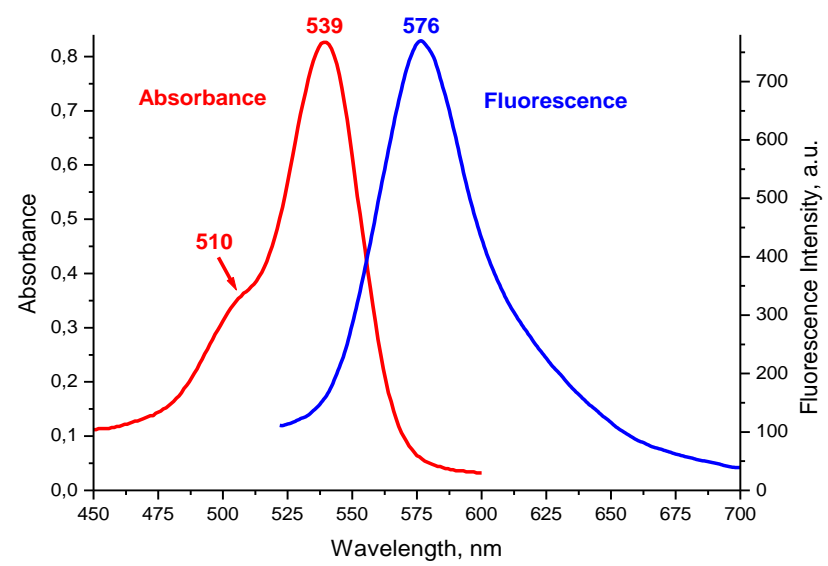

Fig 2. Absorption and fluorescence spectra of a polymer film with Rh6G.

Table 3. Growing parameters of barley after pre-sowing treatment by polymer coating including metal NPs or salts.

\begin{tabular}{|c|c|c|c|c|c|}
\hline № groups & $\begin{array}{l}\text { The compositions for caryopsis } \\
\text { coating }\end{array}$ & $\begin{array}{c}\text { Seed germination*, (3 } \\
\text { days), \% }\end{array}$ & $\begin{array}{c}\text { Seed germination*, (7 } \\
\text { days.), \% }\end{array}$ & $\begin{array}{l}\text { Fresh mass**, } \\
\text { exp/cont, \% }\end{array}$ & $\begin{array}{c}\text { Root mass**, exp/cont, } \\
\%\end{array}$ \\
\hline control & Polymers film without metal NPs & $85.9 \pm 7.8 \mathrm{a}$ & $95.1 \pm 4.5 \mathrm{a}$ & $101 \pm 3.4 \mathrm{a}$ & $99 \pm 4.2 \mathrm{a}$ \\
\hline 1. & $\begin{array}{l}\text { Polymers film with metal NPs } \\
\text { (Fe10-6 \%+Zn 10-4 \%+Cu 10-8\%) }\end{array}$ & $87.8 \pm 1.9 \mathrm{a}$ & $94.8 \pm 1.0 \mathrm{a}$ & $117.5 \pm 2.3 b$ & $116 \pm 1 b$ \\
\hline 2. & $\begin{array}{l}\text { Polymers film with metal NPs } \\
\text { (Fe10-8 \%+Zn 10-4 \%+Cu 10-8\%) }\end{array}$ & $81.0 \pm 2.7 \mathrm{a}$ & $96.2 \pm 1.2 \mathrm{a}$ & $121.1 \pm 2.6 \mathrm{~b}$ & $119.1 \pm 3.4 \mathrm{~b}$ \\
\hline 3. & $\begin{array}{l}\text { Polymers film with metal NPs } \\
(\text { Fe10-8\%+Zn } 10-3 \%+C \text { u } 10-8 \%)\end{array}$ & $76.7 \pm 4.8 \mathrm{a}$ & $90.1 \pm 1.8 \mathrm{a}$ & $102.0 \pm 2.1 a$ & $111.3 \pm 4.4 \mathrm{ab}$ \\
\hline 4. & $\begin{array}{l}\text { Polymers film with salts (Fe10-8 } \\
\%+\operatorname{Zn} 10-4 \%+\mathrm{Cu} 10-8 \% \text { ) }\end{array}$ & $68.2 \pm 3.9 \mathrm{ab}$ & $83.9 \pm 1.2 \mathrm{ab}$ & $101.4 \pm 3 a$ & $112,1 \pm 12 a b$ \\
\hline
\end{tabular}

* Experimental data were counted as a percentage of germinated seeds against number of sawed (\%).

** Experimental data were counted as a ratio of treated values against control (\%). Sprout fresh mass and root mass were calculated as [total mass/number of germinated seeds]

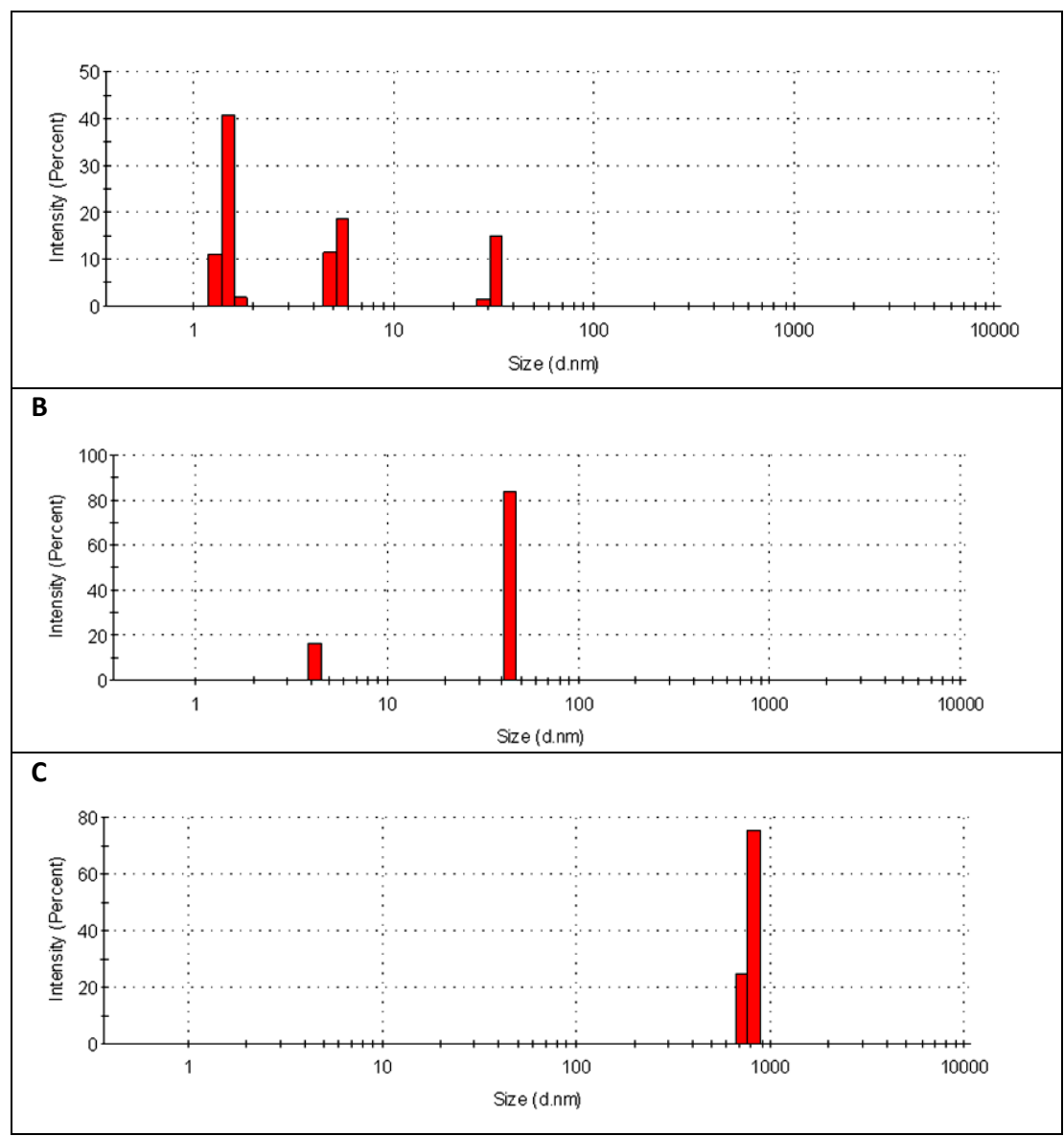

Fig 3. Particle size distribution (DLS data) in the polymer solution (A), in the polymer solution with Zn NPs (10- $\left.{ }^{4} \%\right)(B)$; in the polymer solution with Zn NPs and Rh6G $(50 \mu \mathrm{M})(\mathrm{C})$. 


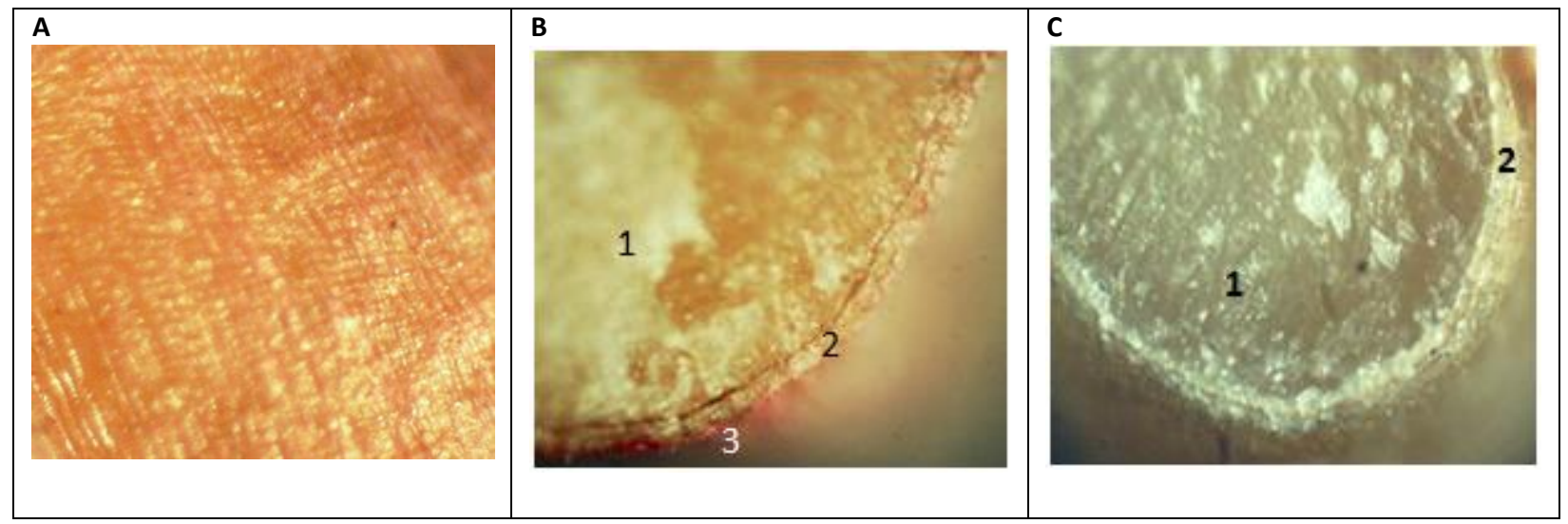

Fig 4. Optical microscopy (at 50x magnification) images of the seed surface coated with a polymer film (A), cross-section of seed: coated with a polymer film (B) and control (C). 1-endosperm structure, 2 - shell, 3- polymer coating.
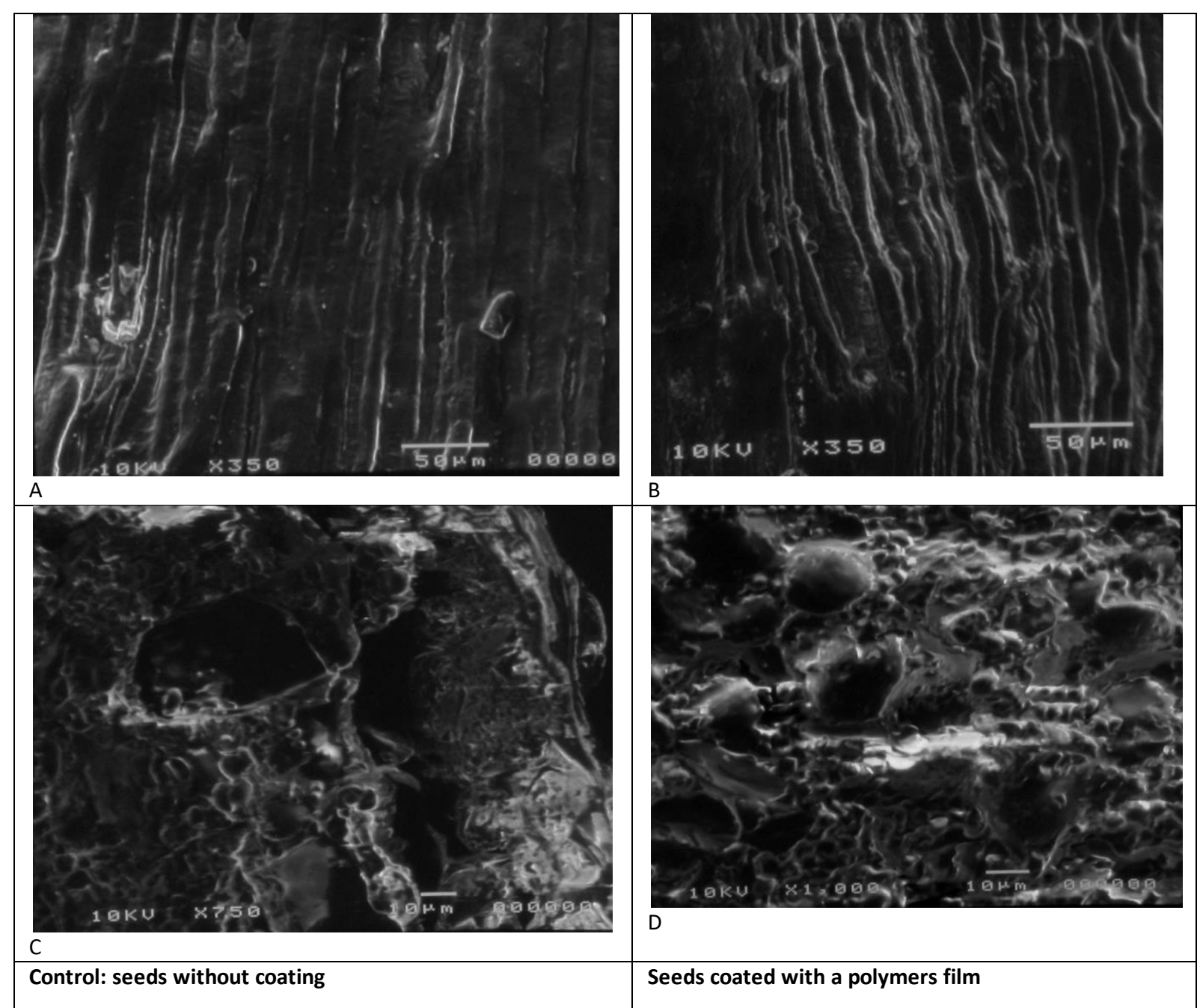

Control: seeds without coating

Seeds coated with a polymers film

Fig 5. Scanning electron microscopy images of none-treated (A) and coated with polymer (B) barley seeds surfaces; endosperm structures in seeds without (C) coating and in treated with polymer film (D). 


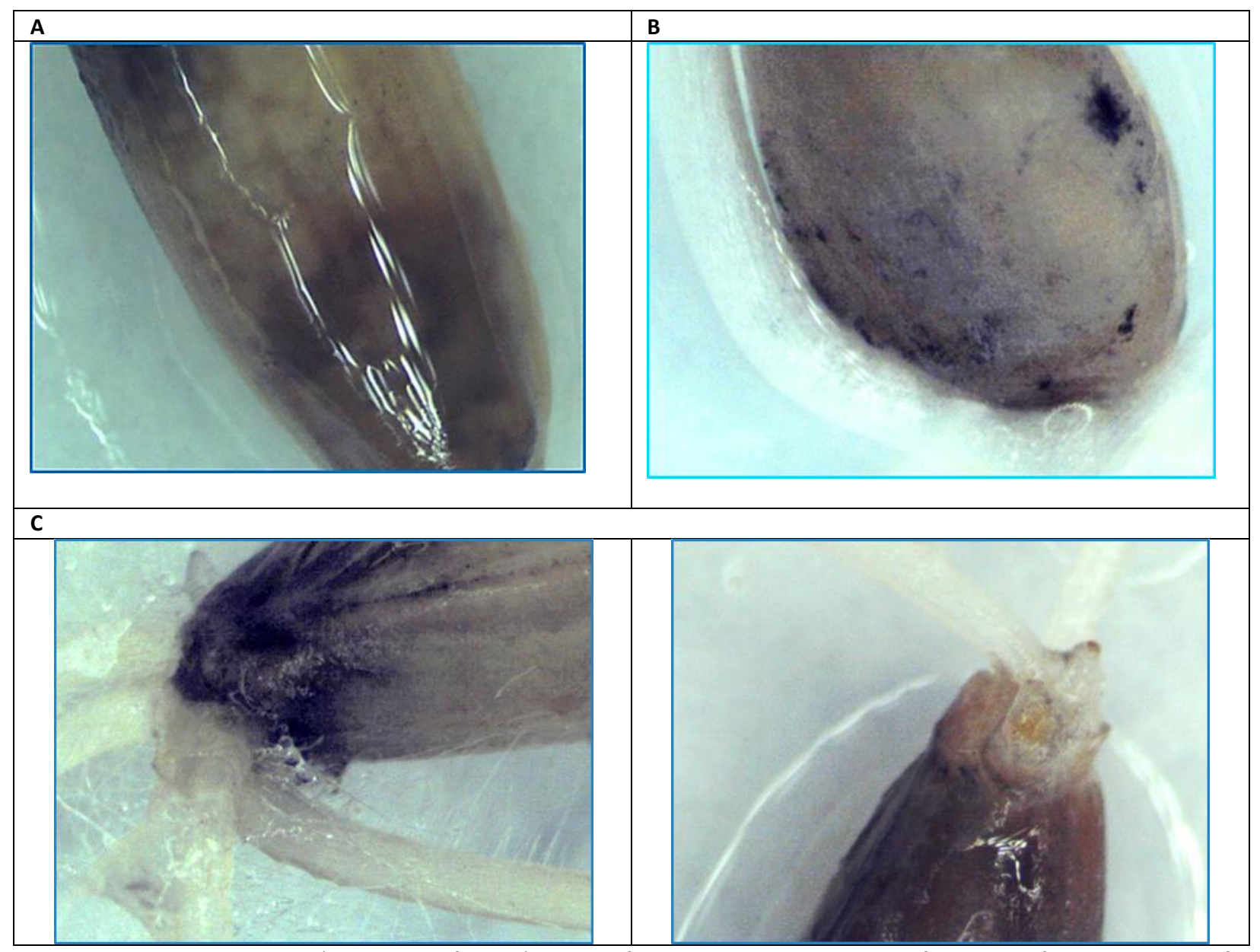

Fig 6. Optical microscopy (at 50x magnification) images of seeds coated with a polymer film: the uniform distribution of the film over the surface (A); the micro cracks being closed by the film (B) and non-disturbed seed germination (C).

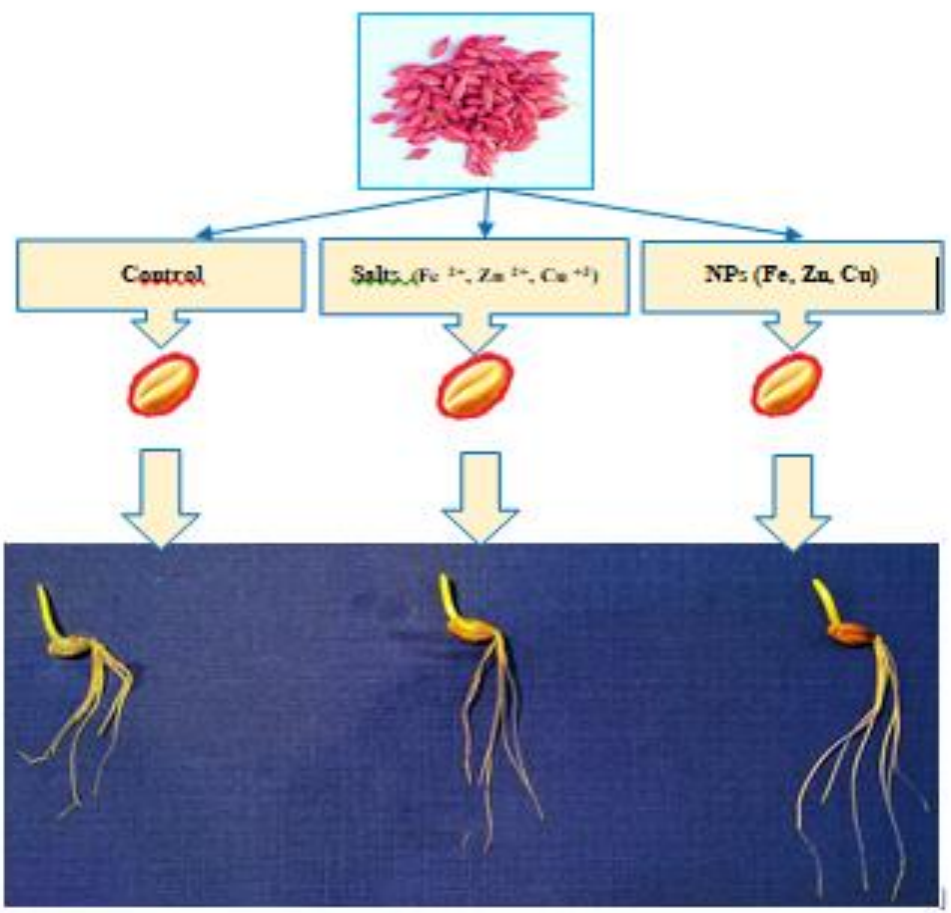

Fig 7. Illustration of germinated barley seeds (the 3rd day): control sample (treated by polymer film without metal) (A); treated with: the polymer coating including metal salts (B) or NPs of iron, zinc and copper NPs in concentrations of $10^{-6} \%$, $10^{-4} \%$ and $10^{-8} \%$ (C). 


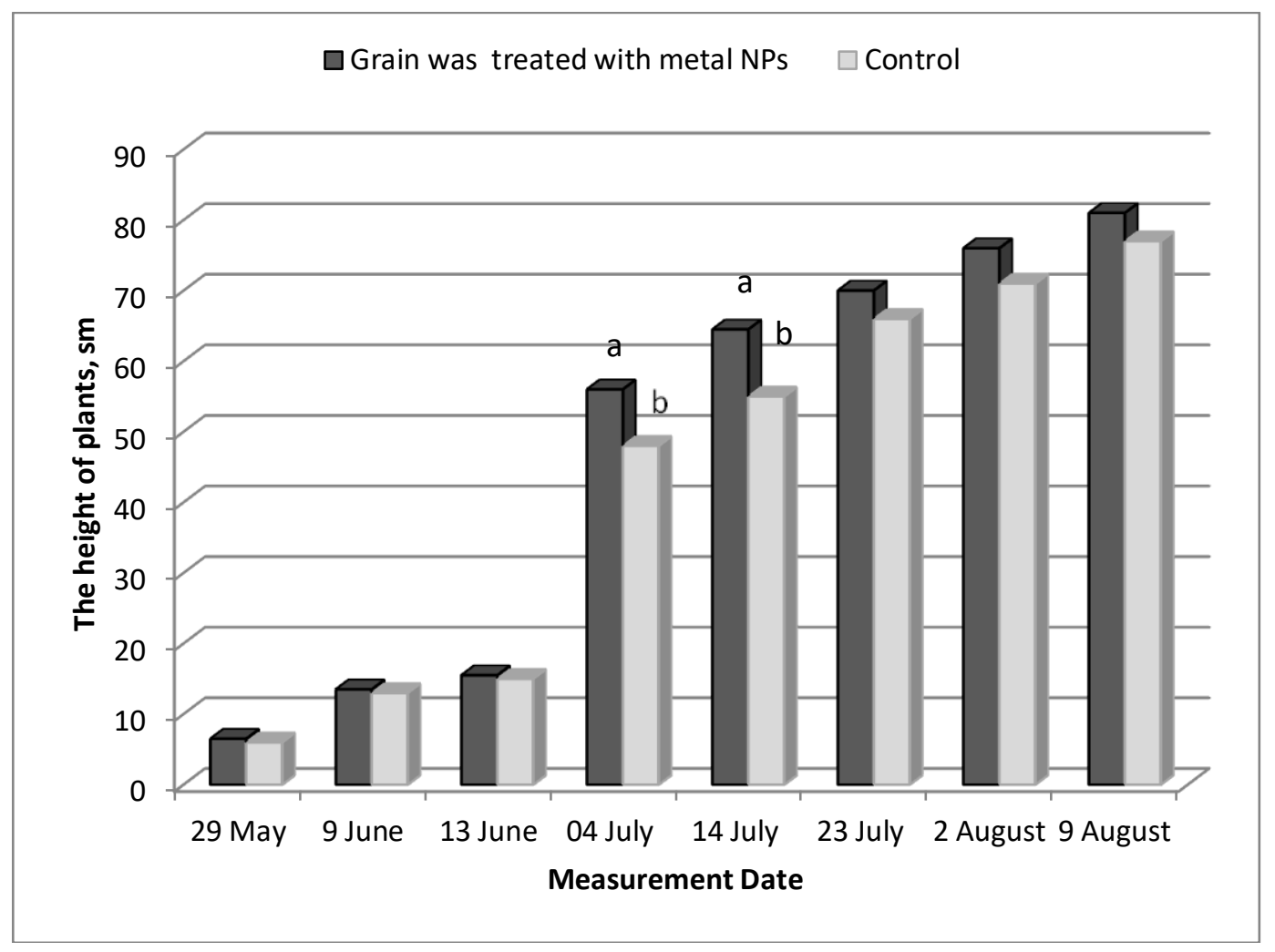

Fig 8. Spring barley stem height in experimental and control groups while growth under field conditions.

day as compared with the control and seeds treated by coating containing metal sulfates in the same concentration (Fig. 7).

Thus, a composition of Fe: Zn: Cu NPs with $10^{-8}: 10^{-4}: 10^{-8}$ (\%) concentrations was selected for pre-sowing treatment of barley for field trials.

\section{Field trials of spring barley after pre-sowing treatment by polymer coating with NPs}

The technology of pre-sowing treatment was based on laboratory trials. The pre-sowing processing of barley with metal NPs does not disturb the usual procedure of presowing treatment in agriculture. Barley seeds of the Nur cultivar were sown on May 6, 2017. The barley growth after treatment with metal NPs is presented in Fig.8.

It can be seen that 2 months after sowing and by the time of full shoots emerge, in the pre-harvest period, the height of plants from seeds treated with metal NPs exceeded the height of plants of the control group by up to $8 \mathrm{~cm}$.

In addition, it was shown that the weight of a thousand seeds is $3.8 \%$ higher in the treated group in comparison with the control. The crop yield from the treated barley is $4.1 \%$ higher than in the control. The moisture content of the bunker grain from the experimental group is $2.2 \%$ lower than in the control group and so can contribute to energy saving in the grain drying process.

Thus, the data indicate the potential of the pre-sowing seed treatment with metal NPs in agriculture.

\section{Discussion}

NPs with unique properties can modulate physiological and biochemical processes, photosynthesis, breathing, nitrogen metabolism, transport, etc. in plants. The researchers use a wide range of nanomaterials to stimulate the growth and increase the productivity of plants. The studied nanomaterials can compose a new group of agrochemical nano-fertilizers (Pradhan and Mailapalli, 2017). On the other hand, the high reactivity of NPs can lead to undesirable environmental consequences such as changes in the physical and chemical soil parameters, including $\mathrm{pH}$, content of active forms of macro- and microelements, modification of habitat of microorganisms, leading to quantitative and qualitative disruption of soil microbiota (Dimkpa, 2014; Simonin and Richaume, 2015; Achari and Kowshik, 2018).

Physicochemical properties: size, shape, phase ratio of NPs affect the manifestation of their biological effects (Rakhmetova et al., 2010; Bogoslovskaja et al., 2014). We studied how NPs of vital elements affect growth, development and crop yield of barley. A composition with iron, zinc, copper NPs inserted in polymer coating was created. The main function of preparation is to form a protective hydrophilic polymer coating on seed surface for defense from external stress factors and pathogens. The coating ensures the preservation of seed nutritional components, containing additional nutrition. It also prevents metal NPs from entering into the soil in order to avoid changes in natural elemental content and to preserve microbiota. In addition, seeds with a film on the surface have more convenient sowing properties (better uniformity and fluidity, reduced spread of dust).

The polymer film is a micro-heterogeneous structure with dispersed of metal NPs and dye aggregates. Strong binding the dye to the polymer matrix helps to demonstrate uniform staining of the film on the seed surface. Hydrophilic polymer ensures effective swelling of seeds and does not disturb germination. It covers the caryopsis surface with a continuous layer less than 10 microns thick, protecting it from the potentially harmful environment and preventing NPs from entering the soil. 
For each crop variety, depending on seed structure, the germination process requires individual conditions. Seed germination is preceded by swelling. The percentage of absorbed moisture differs for various species and cultivars. In some cases, it is important to reduce the period of the seed swelling process to minimize drought stress (Thabet et al., 2018). Various physical and chemical processes, such as magnetization, ozonation, electrochemical activation, acidity control, trace elements, etc. improve moisture penetration through the shell, thus, activating biological processes in seeds (Kornarzyński et al., 2018, Penuelas et al., 2004).

An increase in seed moisture after incubation with iron NPs and active seed germination was observed by (Azamal and Khwaja, 2014). The positive effect of copper and iron NPs on seed germination may be due to the participation of metal ions, which are formed in water and biological media. NPs oxidation in Fenton reactions generate $\mathrm{OH} \cdot$ radicals inducing loosening of the seed cell wall and lead to active water transport (Kim et al., 2014). A comparative study of iron sulfate and iron NPs effects on the process of barley swelling showed that changes in moisture content and seed mass during swelling is intensified under the action of salt. But the germination and development of plants impairs. It turned out, as shown in the study (Gorim and Asch, 2017), that rapid absorption of moisture by seeds leads to an anoxia in the developing embryonic tissues, which is an inhibiting factor for the growth of seedlings.

There are some seed coatings with hydrophilic materials or hydro absorbents, providing the optimal amount of water necessary for germination and development of plants, but limiting oxygen supply to germinating seeds and, thus, inhibiting the growth (Gorim and Asch, 2017). In our composition, hydrophilic polymer coating with metal NPS besides seed defense is targeted to be biological active due to metal NPs. It was shown that NPs effects are due to their ability of active penetration and spreading throughout (Mahajan et al., 2011). Biological activity of metal NPs cannot be associated with any single parameter (for example, particle size or crystalline metal content in the core), but with a complex of peculiarities (Yuan et al., 2018). The fact is that one of the characteristic features of metal NPs from different sources is their variability: structural and shape diversity, size, elemental composition, thickness of the oxide film on the particle surface, the content of crystalline metal in the core, and mass content of oxygen. These NPs parameters depend not only on the method of their production, but also on the stage and mode of formation of nanostructures, as well as on the effects of surface modification. That was demonstrated in our studies with copper NPs synthesized by high-temperature condensation (Rakhmetova et al., 2010; Bogoslovskaja et al., 2014). That is why the target synthesis of metal NPs with pronounced biological activity and the mandatory certification of NPs based on physical and chemical parameters are necessary for their successful use in agriculture. Fe, Zn, Cu NPs listed in Table 3 exhibit high biological activity, as evidenced by the presented results of our laboratory and field tests.

Considering the mechanism of stimulation of seed germination and early growth of barley under the presowing treatment with metal NPs in the polymer coating as compared to the control group, we assume that the effective action of NPs is related to their ability to active penetration. The influence on the targets of biological action contributes to a more effective course of physiological and biochemical processes of germination and further growth Thus, the created composition forms a uniform 10 micronthick micro-heterogeneous polymer structure with dispersed metal NPs and dye aggregates on seed surface. The polymer film covers spots of micro traumas on caryopsis, isolating it from pathogens and does not disrupt the germination process. Laboratory studies (germination, changes in FM and RM) and results of biometric observations in the field demonstrated that this method of pre-sowing seed treatment provides a significant starting effect, reducing the germination time and guarantees healthy shoots and active plant growth. Iron, zinc and copper NPs composition at 10 $8 \%, 10^{-4} \%$ and $10^{-8} \%$ concentrations increased FM and RM of barley in laboratory experiments. In field trials, it stimulated barley crop yields and decreased the moisture content of the bunker grain, compared with the control.

Consequently, the obtained data proves that the pre-sowing seed treatment with metal NPs in the polymer coating is a promising practice for agriculture.

\section{Materials and methods}

Our experimental object was spring barley (Hordeum vulgare L.) of "Nur" cultivar.

\section{Experiment location}

The experiment was performed at the V.L. Talrose Institute for Energy Problems of Chemical Physics at N.N. Semenov Federal Research Center for Chemical Physics, Russian Academy of Sciences, Russian Federation. Harvest tests were carried out in the Moscow region (Lugovaya farm), Russian Federation.

\section{Experimental design}

Experiments were performed with 16 treatments in 4 replications, 25 seeds in each.

Treatment groups:

I). Control 1 - non treated seeds.

II). Control 2 -seeds coated by polymer film without metal salts or NPs.

III). Seeds coated by polymer film with Fe NPs: $3 a) \cdot 10^{-4} \%$; 3b). $10^{-6} \%$; 3c) $\cdot 10^{-8} \%$; 3d). $10^{-10} \%$.

IV). Seeds coated by polymer film with Zn NPs: $4 a) \cdot 10^{-4} \%$; 4b). $10^{-5} \%$; 4 c). $10^{-6} \%$.

V). Seeds coated by polymer film with Cu NPs: $5 a) \cdot 10^{-6} \%$; 5b). $10^{-7} \%$; $\left.5 \mathrm{c}\right) .10^{-8} \%$.

VI). Seeds coated by polymer film with metal NPs Fe10 ${ }^{-6}$ $\%+Z n 10^{-4} \%+C u 10^{-8} \%$.

VII). Seeds coated by polymer film with metal NPs Fe10 ${ }^{-8}$ $\%+\operatorname{Zn~} 10^{-4} \%+\mathrm{Cu} 10^{-8} \%$

VIII). Seeds coated by polymer film with metal NPs Fe10-8 $\%+\operatorname{Zn~} 10^{-3} \%+C u 10^{-8} \%$.

IX). Seeds coated by polymer film with metal salts. Ion concentrations: Fe10 $\%+\mathrm{Zn} 10^{-4} \%+\mathrm{Cu} 10^{-8} \%$.

\section{NPs certification}

Iron, zinc and copper NPs were obtained by hightemperature condensation method (Gen and Miller, 1981) with the Migen-3 facilities (Leipunsky et al., 2019) in V.L. Talrose Institute for Energy Problems of Chemical Physics. The shape and size of metal NPs were determined by 
electron microscopy on a Joel JSM 7401F scanning electron microscope at $1 \mathrm{kV}$ voltage. To estimate the average diameter of NPs, micrographs were processed using Micran 25 software by measuring the diameter of at least a thousand particles. Based on the data obtained, size distributions of metal NPs were calculated.

The X-ray phase analysis of metal NPs was performed on an ADP-1 X-ray analyzer (RU) through $\mathrm{Co} \mathrm{H}-\alpha$ radiation with a 0.05 o scan step and a signal accumulation time of 8-10 minutes. To get the phase composition of metal NPs, the obtained interference peaks were processed using Match 3.8.0.137 software.

\section{The polymer coating preparation}

To get a polymer film, a mixture of sodium salt of carboxymethyl cellulose ( $\mathrm{Na}-\mathrm{CMC}$, MW 250 000, DS = 0.9) solution and low molecular weight polyethylene glycol (PEG400, MW 400) with EDTA-Na 2 (Sigma)) in proportion 1:2.5 $(\mathrm{v} / \mathrm{v})$ was dissolved in distilled water. Cationic dye of xanthene series rhodamine $6 \mathrm{G}$ (Rh6G) $\left(\mathrm{C}_{28} \mathrm{H}_{31} \mathrm{ClN}_{2} \mathrm{O}_{3}\right)$ was added to visualize the seed surface.

Metal NPs samples were dispersed in distilled water with an ultrasonic disintegrator "ScientzJY 92-IIN" (China) in the 0.5 A mode; $44 \mathrm{kHz}$; time - $30 \mathrm{~s}$; break $30 \mathrm{~s}$ (repeat - 3 times) under cooling with ice, added to the polymer mixture and stirred.Metal sulfates $\mathrm{FeSO}_{4} \times 7 \mathrm{H}_{2} \mathrm{O}, \quad \mathrm{ZnSO}_{4} \times 7 \mathrm{H}_{2} \mathrm{O}$, $\mathrm{CuSO}_{4} \times 5 \mathrm{H}_{2} \mathrm{O}$ (Sigma) were dissolved in distilled water, metal ions concentrations being $\mathrm{Fe} 10^{-8} \%+\mathrm{Zn} 10^{-4} \%+\mathrm{Cu} 10^{-8} \%$.

To get absorption and emission spectra of films with NPs, the samples were placed on a quartz substrate and recorded by a Hach DR-4000V spectrophotometer (Hach-Lange, USA) and a Perkin Elmer LS-50 fluorescent spectrometer (Perkin Elmer, USA). The fluorescence excitation wavelength was $500 \mathrm{~nm}$. Film thickness was $10 \mu \mathrm{m}$, the dye concentration in films $-5 \mathrm{mM}$. The particle size distribution in the samples was estimated by dynamic light scattering on a Zetasizer Nano-S device (Malvern Instruments, UK). Dynamic viscosity of the solution was equal to $1300 \mathrm{mPa} \cdot \mathrm{s}$.

\section{Microscopy}

Optical micrographs of the surface and cross sections of seeds were obtained using a BS-702B binocular optical microscope with a digital USB camera. Electron micrographs were taken on a Jeol JSM-T330A scanning electron microscope at an accelerating voltage of $10 \mathrm{kV}$.

\section{Barley seed germination method}

The roll method was used for barley seeds germination tests. Rolls of filter sterilized paper with 25 seeds on each, $2.5 \mathrm{~cm}$ from the top, were placed in a vertical position in germination vessels in a dark ventilated climate chamber. The temperature was maintained at $20^{\circ} \pm 1^{\circ} \mathrm{C}$. There were 4 rolls in each experimental series.

An assessment of seed germination in control and treated groups was made after 3 and 7 days. Germination after 3 days was scored when radicle had emerged from the seed coat and achieved seed length. After 7 days, final germination percent was calculated. The properly germinated seeds had to have at least two normally developed roots longer than the seed length and a sprout length of at least equal to seed length. Stems and roots were cut on 7th day and FM and RM were assessed.

\section{Barley cultivation in the field}

Field tests were carried out at 67 hectares. Spring processing of the field was carried out on May 5, 2017 using a John Deer 8420 combined unit to a depth of $15 \mathrm{~cm}$.

The podzolic soil with $25 \mathrm{~cm}$ humic horizon capacity had humus content $-2.2 \%$, mobile phosphorus - $46.6 \%$, exchangeable potassium - $22.8 \%$. Soil $\mathrm{pH}$ was 5.6 , calcium $8.9 \mathrm{mg} / \mathrm{kg}$, magnesium - $3.7 \mathrm{mg} / \mathrm{kg}$, boron - $1.0 \mathrm{mg} / \mathrm{kg}$. The average day/night air temperature in May, June, July, August and September in the Lugovaya farm was $\left({ }^{\circ} \mathrm{C}\right): 18.5 / 1.9$, 20.5/6.1, 25.1/10.6, 23.5/11.1, 19.5/6.4, respectively. Monthly precipitation (mm) averages - 84.1 (May), 133.2 (June), 110.6 (July), 68 (August), 37.9 (September). Location of plots was regular, experimental plot being placed between control ones. Plot areas were $50.400 \mathrm{~m}^{2}$ each.

The pre-sowing preparation of barley seeds was carried out on May 5, 2017 by the seed treating aggregate. A combination of NPs Fe: $\mathrm{Zn}$ : $\mathrm{Cu}$ was added to the basic preparations. Control seeds were processed as usual.

All technological operations on the test and control plots were carried out simultaneously. To run out phenological and biometric observations, three monitoring sites $1 \mathrm{~m}^{2}$ each were isolated.

\section{Statistical analysis}

All results are presented as a mean $\pm \mathrm{SE}$. Experimental data were calculated as a proportion of test measurements against control ones (\%). Statistica 20.0 was used for data analysis. Significant effects $(p \leq 0.05)$ were verified by Tukey's test.

\section{Conclusion}

We have created and studied a coating containing metal NPs for pre-sowing treatment of barley seeds instead of commonly used metal salts or complexes. Neutral NPs at biotic doses as individually or in compositions were introduced into the polymer film. Germination was stimulated in seeds coated with such preparations and gain in root and sprout fresh mass was observed, depending on NPs nature and concentration. Field tests showed that presowing treatment with metal NPs results in an increase in plant height and grain yield in barley, improving grain quality. Electron-microscopic control showed that such coating is evenly distributed over the seed surface, covering micro traumas, defending from damages and does not disturb germination. The structure of the endosperm remained intact. Seed surfaces after treatment were uniform and the defects and irregularities were smoothed. Thus, the proposed method of metal NPs introduction into a polymer coating for pre-sowing seed treatment can be useful for agriculture.

\section{Acknowledgements}

Authors are grateful to the Ministry of Education and Science of the Russian Federation for support of this work. Authors thank the head Dr. A.N. Jigach and the staff of the Laboratory of V.L. Talrose Institute for Energy Problems of Chemical Physics at N.N. Semenov Federal Research Center for Chemical Physics, RAS). Authors are grateful for the 
spectroscopic measurements, the SEM and DLS to $M$. Gradova and O. Gradov N.N. (Semenov Federal Research Center for Chemical Physics, RAS).

\section{References}

Achari GA and Kowshik M (2018) Recent Developments on Nanotechnology in Agriculture: Plant Mineral Nutrition, Health, and Interactions with Soil Microflora. J Agric Food Chem. 66: 8647-8661.

Alghuthaymi MA, Almoammar H, Rai M, Said-Galiev E, AbdElsalam KA (2015) Myconanoparticles: synthesis and their role in phytopathogens management. Biotechnol Biotechnol Equip. 29: 221-236.

Azamal H and Khwaja SS (2014) Phytosynthesis of nanoparticles: concept, controversy and application. Nanosc Res Lett. 229: 111.

Bhagat Y, Gangadhara K, Rabinal C, Chaudhari G, Ugale P (2015) Nanotechnology in agriculture: a review. J Pure App Microbiol. 9: 737-747.

Bindraban PS, Dimkpa C, Nagarajan L, Roy A, Rabbinge R (2015) Revisiting fertilisers and fertilisation strategies for improved nutrient uptake by plants. Biol Fertil Soils. 51: 897-911.

Bogoslovskaja OA, Rakhmetova AA, Ovsyannikova MN, Olkhovskaya IP, Gluschenko NN (2014) Antibacterial effect of copper nanoparticles with differing dispersion and phase composition. Nanotech Rus. 9: 82-86.

Dasgupta N, Ranjan S, Mundekkad D, Ramalingam C, Shanker R, Kumar A (2015) Nanotechnology in agro-food: from field to plate. Food Res Int. 69: 381-400.

Dimkpa CO (2014) Can nanotechnology deliver the promised benefits without negatively impacting soil microbial life? J Basic Microbiol. 54: 889-904.

Duhan JS, Kumar R, Kumar N, Kaur P, Nehra K, Duhan S (2017) Nanotechnology: The new perspective in precision agriculture. Biotechnol Rep (Amst). 15: 11-23.

Elsharkaway M and Derbalah A (2018) Antiviral activity of titanium dioxide nanostructures as a control strategy for broad bean strain virus in faba bean. Pest Manag Sci. DOI: 10.1002/ps.5185.

El-Temsah YS and Joner EJ (2012) Impact of Fe and Ag nanoparticles on seed germination and differences in bioavailability during exposure in aqueous suspension and soil. Environ Toxicol. 27: 42-49.

Feng Y, Cui X, He S, Dong G, Chen M, Wang J, Lin X (2013) The role of metal nanoparticles in influencing arbuscular mycorrhizal fungi effects on plant growth. Environ Sci Technol. 47: 9496-9504.

Guen MY and Miller AV (1983) Flow-levitation method for synthesis of ultrafine metal powders. Phys Chem Mech Surf. 2:150-154.

Ghormade V, Deshpande MV, Paknikar KM (2011) Perspectives for nano- biotechnology enabled protection and nutrition of plants. Biotechnol Adv. 29: 792-803.

Glushchenko NN, Bogoslovskaya OA, Ol'khovskaya IP (2002) Physicochemical regularities of the biological effect of highly disperse metal powders. Rus J Phys Chem. 21: 79-85.

Gorim L and Asch F (2017) Seed coating increases seed moisture uptake and restricts embryonic oxygen availability in germinating cereal seeds. Biology (Basel). 6: 31-45.

Handford CE, Dean $M$, Henchion $M$, Spence $M$, Elliott $C T$, Campbell K (2014) Implications of nanotechnology for the agri-food industry: opportunities, benefits and risks. Trends Food Sci Technol. 40: 226-241.

Khot LR, Sankaran S, Maja JM, Ehsani R, Schuster EW (2012) Applications of nanomaterials in agricultural production and crop protection: a review. Crop Prot. 35: 64-70.

Kim JH, Lee Y, Kim EJ, Gu S, Sohn EJ, Seo YS (2014) Exposure of iron nanoparticles to arabidopsis thaliana enhances root elongation by triggering cell wall loosening. Environ Sci Technol. 48: 3477-3485.

Kornarzyński K, Dziwulska-Hunek A, Kornarzyńska-Gregorowicz A, Sujak A (2018) Effect of Electromagnetic Stimulation of Amaranth Seeds of Different Initial Moisture on the Germination Parameters and Photosynthetic Pigments Content. Sci Rep. 8: 14023.

Leipunsky IO, Zhigach AN, Kuskov ML, Berezkina NG, Afanasenkova ES, Kudrov BV, Lopez GW, Vorobjeva GA, Naumkin AV (2019) Synthesis of TiH2 nanopowder via the Guen-Miller Flow-Levitation method and characterization. J Alloys Compd. 778: 271-279.

Ma C; White JC, Zhao J, Zhao Q, Xing B (2018) Uptake of engineered nanoparticles by food crops: characterization, mechanisms, and implications. Annu Rev Food Sci Technol. 9: 129-153.

Mahajan P, Dhoke SK, Khanna AS (2011) Effect of nano-ZnO particle suspension on growth of mung (Vigna radiata) and gram (Cicer arietinum) seedlings using plant agar method. J Nanotechnol. 1:1-7.

Mehmood A (2018) Brief overview of the application of silver nanoparticles to improve growth of crop plants. IET Nanobiotech 12(6):701-705.

Penuelas J, Llusia J, Martinez B (2004) Diamagnetic susceptibility and root growth responses to magnetic fields in lens culinaris, glycine soja, and triticum aestivum. Electromagnetic Biologu and Medicine. 23: 97-112.

Pradhan S and Mailapalli DR (2017) Interaction of engineered nanoparticles with the agri-environment. J Agric Food Chem. 65(38): 8279-8294.

Rakhmetova AA, Alekseeva TP, Bogoslovskaya OA, Leipunskii IO, Ol'khovskaya IP, Zhigch AN, Glushchenko NN (2010) Woundhealing properties of copper nanoparticles as a function of physicochemical parameters. Nanotech Rus. 5: 271-276.

Rakhmetova AA, Bogoslovskaja OA, Olkhovskaya IP, Zhigach AN, Ilyina AV, Varlamov VP, Gluschenko NN (2015) Concomitant action of organic and inorganic nanoparticles in wound healing and antibacterial resistance: chitosan and copper nanoparticles in an ointment as an example. Nanotech Rus. 10: $149-156$.

Razzaq A, Ammara R, Jhanzab HM, Mahmood T, Hafeez A, Hussain S (2016) A novel nanomaterial to enhance growth and yield of wheat. J Nanosci Technol. 2(1): 55-58.

Ruttkay-Nedecky B, Krystofova O, Nejdl L, Vojtech A (2017) Nanoparticles based on essential metals and their phytotoxicity. J Nanobiotech. 15 (33): 1-19.

Simonin M and Richaume A (2015) Impact of engineered nanoparticles on the activity, abundance, and diversity of soil microbial communities: a review. Environ Sci Pollut Res Int. 22: 13710-13723.

Thabet SG, Moursi YS, Karam MA, Graner A, Alqudah AM (1918) Genetic basis of drought tolerance during seed germination in barley. PLoS ONE. 13(11): e0206682.

Yuan J, Chen Y, Li H, Lu J, Zhao H, Liu M, Nechitaylo GS, Glushchenko NN (2018) New insights into the cellular responses to iron nanoparticles in Capsicum annuum. Sci Rep. 8(1): 3228-3236.

Zhao H, Liu M, Chen Y, Lu J, Li H, Sun Q, Nechitaylo GS, Bogoslovskaya OA, Olkhovskaya IP, Glushchenko NN (2019) Pepper plants response to metal nanoparticles and chitosan in nutrient media. Aust J Crop Sci. 13: 433-443. 